\title{
Nidificação e forrageamento de Centris (Ptilotopus) maranhensis Ducke (Hymenoptera, Apidae, Centridini)
}

\author{
Marina Ramos; Fernanda Mendes; Patrícia Albuquerque \& Márcia Rêgo
}

Universidade Federal do Maranhão. Avenida dos Portugueses, Bacanga, 65085-580 São Luís, Maranhão, Brasil.

\begin{abstract}
Nesting biology and foraging of Centris (Ptilotopus) maranhensis Ducke (Hymenoptera, Apidae, Centridini). The bees belonging to the tribe Centridini possess distribution neotropical and are considered the main pollinators of different plant species in different biomas. Despite of this the biology data of the majority of species remain scarce. This work is about observations of biology of Centris (Ptilotopus) maranhensis Ducke, 1910, specie that occurs in the Northeast of Brazil. The study was made in a cerrado area in the State of Maranhão during a period of adult activity. Females were seen nesting at epigeous termite nests and visiting Byrsonima umbellata Mart. (Malpighiaceae) flowers for oil collection. The behavior was directly registered and shooted. The nests were excavated being scraped the substratum until the cells were found. A complete nest was opened for examination of the internal structures and analysis of cells content. The general structure presented a main tunnel with cells descending linearly. Cells $(n=5)$ with larvae in different periods of development were found. A firmly pollen paste was seen where a huge Byrsonima grains was verified.
\end{abstract}

KEY WORDS. Cerrado; nests; termite nests.

RESUMO. As abelhas pertencentes à tribo Centridini possuem distribuição neotropical e são consideradas os principais polinizadores de diversas espécies vegetais em diferentes biomas. Apesar disso, dados sobre a biologia da maioria das espécies ainda são escassos. Este trabalho relata observações sobre a biologia de Centris (Ptilotopus) maranhensis Ducke, 1910, uma espécie que ocorre no Nordeste do Brasil. O estudo foi conduzido em uma área de cerrado no Estado do Maranhão durante o período de atividade dos adultos. Fêmeas foram observadas nidificando em termiteiros epígeos e em visita às flores de Byrsonima umbellata Mart. (Malpighiaceae) para coleta de óleo. $\mathrm{O}$ comportamento foi registrado diretamente e através de filmagens. Os ninhos foram escavados, raspando-se o substrato até as células serem encontradas. Um ninho completo foi aberto para exame das estruturas internas e análise do conteúdo das células. A estrutura geral apresentava um túnel principal com células descendentes dispostas linearmente. Foram encontradas células $(n=5)$ com larvas em diferentes estágios de desenvolvimento e uma massa de pólen de consistência firme e pastosa formada por uma grande quantidade de grãos de Byrsonima. PALAVRAS-CHAVE. Cerrado; ninhos; termiteiros.

Apesar de ser um grupo com distribuição ampla e hábitos de nidificação variados, os estudos sobre a biologia de Centridini (Apidae) ainda são incipientes. No Brasil, as espécies mais estudadas foram aquelas que nidificam em cavidades preexistentes, principalmente em ninhos-armadilha, devido à facilidade oferecida pela técnica. As espécies que nidificam em ninhos-armadilha incluem Centris tarsata Smith, 1874 (SILVA et al. 2001, Aguiar \& Garófalo 2004), C. trigonoides Lepeletier, 1841 (Aguiar et al. 2006), C. vittata Lepeletier, 1841 (Pereira et al. 1999), e C. analis (Fabricius, 1804) (Jesus \& GARÓFALO 2000).

As espécies que fazem seus ninhos no solo ou em termiteiros são pouco estudadas devido à dificuldade em encontrar seus ninhos. Coville et al. (1983) fizeram uma revisão dos hábitos de nidificação do gênero Centris. Na literatura bra- sileira recente, dentre as espécies que nidificam no solo, existem informações sobre C. aenea Lepeletier, 1841 (Aguiar \& Gaglianone 2003), C. flavifrons (Fabricius, 1775) (RÊGo et al. 2006), C. colaris Lepeletier, 1841 (CAmillo et al. 1993) e C. fuscata Lepeletier, 1841 (CAmillo et al. 1993).

Dentre as espécies do subgênero Ptilotopus Klug, 1810 que nidificam em termiteiros arborícolas ou epígeos há registros para C. scopipes Friese, 1899 (Gaglianone 2001), C. sponsa Smith, 1854 (Laroca et al. 1993), C. derasa Lepeletier, 1841 (VezeyFitzgerald 1939, Bennet 1964) e C. nobilis Westwood, 1840 (DucKe 1902 apud GaGLIANONE 2001). Elas são abelhas de grande porte e, como a maior parte dos Centridini, são consideradas polinizadores-chave de diversas espécies vegetais em diferentes ambientes, principalmente das famílias produtoras de óle-

Revista Brasileira de Zoologia 24 (4): 1006-1010, dezembro 2007 
os ou lipídios florais como as Malpighiaceae, Scrophulariaceae e Krameriaceae (Buchmann 1987).

Centris (Ptilotopus) maranhensis Ducke, 1910 foi registrada, na literatura, somente em áreas de caatinga da Paraíba (Aguiar et al. 2003), dunas na Bahia (Viana 1999) e em floresta secundária e cerrado do Maranhão (RebêLo et al. 2003). Neste trabalho são apresentados alguns dados de nidificação, período de atividade e fontes de recursos florais utilizadas no forrageamento de C. maranhensis.

\section{MATERIAL E MÉTODOS}

As observações das fêmeas nos ninhos foram realizadas em 4/VI/2005 e o comportamento nas flores foi observado de maio a agosto de 2005 e 2006, em uma área de cerrado no Município de Urbano Santos $\left(03^{\circ} 12^{\prime} 28^{\prime \prime} S\right.$; $\left.43^{\circ} 24^{\prime} 12^{\prime \prime} \mathrm{W}\right)$, próximo à comunidade de Bom Jesus, Nordeste do Maranhão, Brasil. O clima da região é tropical megatérmico (enquadrando-se no tipo Aw' de acordo com a classificação de Köppen), com pluviosidade anual em torno de $1800 \mathrm{~mm}$, a maior parte concentrada nos meses de dezembro a maio, sendo os meses de julho a outubro muito secos. A temperatura média anual varia entre 26 e $27^{\circ} \mathrm{C}$. Os principais solos são os arenosos (bem drenados e com baixa fertilidade natural), areias quartzosas e latossolos vermelho-amarelo. A vegetação predominante na região é o cerrado, ocorrendo ainda formações como floresta estacional semidecídua e manchas de vegetação mista (Brasil 1984).

Duas fêmeas foram observadas em atividade nos ninhos e inúmeras fêmeas foram acompanhadas durante o forrageamento nas flores, sendo o comportamento delas observado in loco e através de filmagens.

Os ninhos foram escavados com ferramentas de jardinagem e com o auxílio de pincéis, raspando-se o substrato até as células serem encontradas. As células foram retiradas e medidas com régua milimetrada nos seus comprimento e diâmetro. As larvas encontradas nas células foram medidas no seu comprimento. O pólen presente em algumas das células foi retirado, acondicionado em tubos eppendorfs e conservado no freezer. Posteriormente lâminas polínicas foram confeccionadas segundo o Método de Acetólise (ERDTMAn 1969) e identificadas.

Os dados de visita de C. maranhensis nas flores foram obtidos a partir de informações disponíveis procedentes de inventários sistematizados de abelhas, realizados em áreas de caatinga (Cabaceiras, Bahia - Aguiar et al. 2003), cerrado (Barreirinhas, Maranhão - Albuquerque \& MendonçA 1999) e floresta secundária (São Luís, Maranhão - REвêLo 1995).

\section{RESULTADOS}

\section{Local de nidificação e atividades das fêmeas}

Duas fêmeas de $C$. maranhensis foram observadas nidificando em termiteiro epígeo ativo, de Amitermes amifer Silvestrii, 1901 (Isoptera, Termitidae). O termiteiro, que ficava ao redor de uma árvore, em lugar sombreado durante todo o dia, pos- suía cerca de 1,5 m de altura; as entradas dos ninhos das abelhas localizavam-se a 32 e $20 \mathrm{~cm}$ do solo e estavam separadas, entre si, por $28 \mathrm{~cm}$.

Quando os ninhos foram localizados, por volta das 14:00 h, uma das fêmeas estava escavando na entrada de uma cavidade (Fig. 1); a abelha sobrevoava ao redor do termiteiro, saía e voltava alguns minutos depois, sem nenhum recurso visível. Essa fêmea permaneceu realizando aquelas atividades até as observações serem interrompidas, após as 17:00 h. Outra fêmea, com pólen nas escopas, entrou em uma cavidade que se encontrava aberta, permanecendo por alguns minutos no interior dela e saindo novamente. Dezenove dias após essas observações, os ninhos foram escavados e apenas naquele em que a fêmea fora vista entrando com pólen a entrada estava completamente fechada, com terra misturada a um material semelhante a teias de aranhas (Fig. 2). Somente neste foram encontradas células. A fêmea observada escavando a entrada da cavidade abandonou o local antes de construir qualquer célula.

\section{Arquitetura do ninho}

Da entrada do ninho, aproximadamente oval, seguia um canal principal, ascendente, com $5 \mathrm{~cm}$ de extensão. No final deste canal havia uma curvatura que media $3 \mathrm{~cm}$, de onde saia uma galeria vertical descendente, com quatro células; logo ao lado da primeira célula, mais próxima à entrada, havia outra galeria contendo uma única célula, com pólen (Figs 3 e 5). O espaço entre as células estava preenchido com terra compactada.

As células mediam cerca de $3 \mathrm{~cm}$ de comprimento e 1,8 $\mathrm{cm}$ em sua maior largura. Estas foram construídas com um material de coloração escura, semelhante à resina, resistente e rígido, não sendo claramente diferenciadas do substrato ao redor e estando firmemente aderida às paredes do termiteiro. Cupins ativos foram vistos em túneis próximos às células de $C$. maranhensis, porém sem comunicação com elas.

Outros termiteiros foram vistoriados, porém não foi observada nenhuma atividade de nidificação e nenhum outro ninho foi encontrado, embora fêmeas de C. maranhensis tenham sido vistas em flores de Byrsonima umbellata Mart. (Fig. 4), uma espécie de Malpighiaceae muito abundante na área, neste período.

\section{Provisões e estágios imaturos}

A célula superior da galeria vertical apresentava uma larva de $2 \mathrm{~cm}$ de comprimento e pólen preenchendo um pouco menos da metade da célula. Logo abaixo, a segunda célula continha outra larva de tamanho maior, $4 \mathrm{~cm}$ de comprimento, e pólen ocupando $1 / 3$ da mesma. A terceira célula possuía somente pólen e a quarta, uma larva ainda maior, em estágio pré-defecante e sem pólen em seu interior. Esta célula foi parcialmente quebrada, sendo levada ao laboratório, onde a larva chegou a tecer parte do casulo, sem defecar, sendo encontrada algumas semanas depois morta e com fungos. O casulo parcialmente tecido apresentava coloração castanha. As larvas estavam posicionadas com o corpo dobrado, sendo que as regiões 

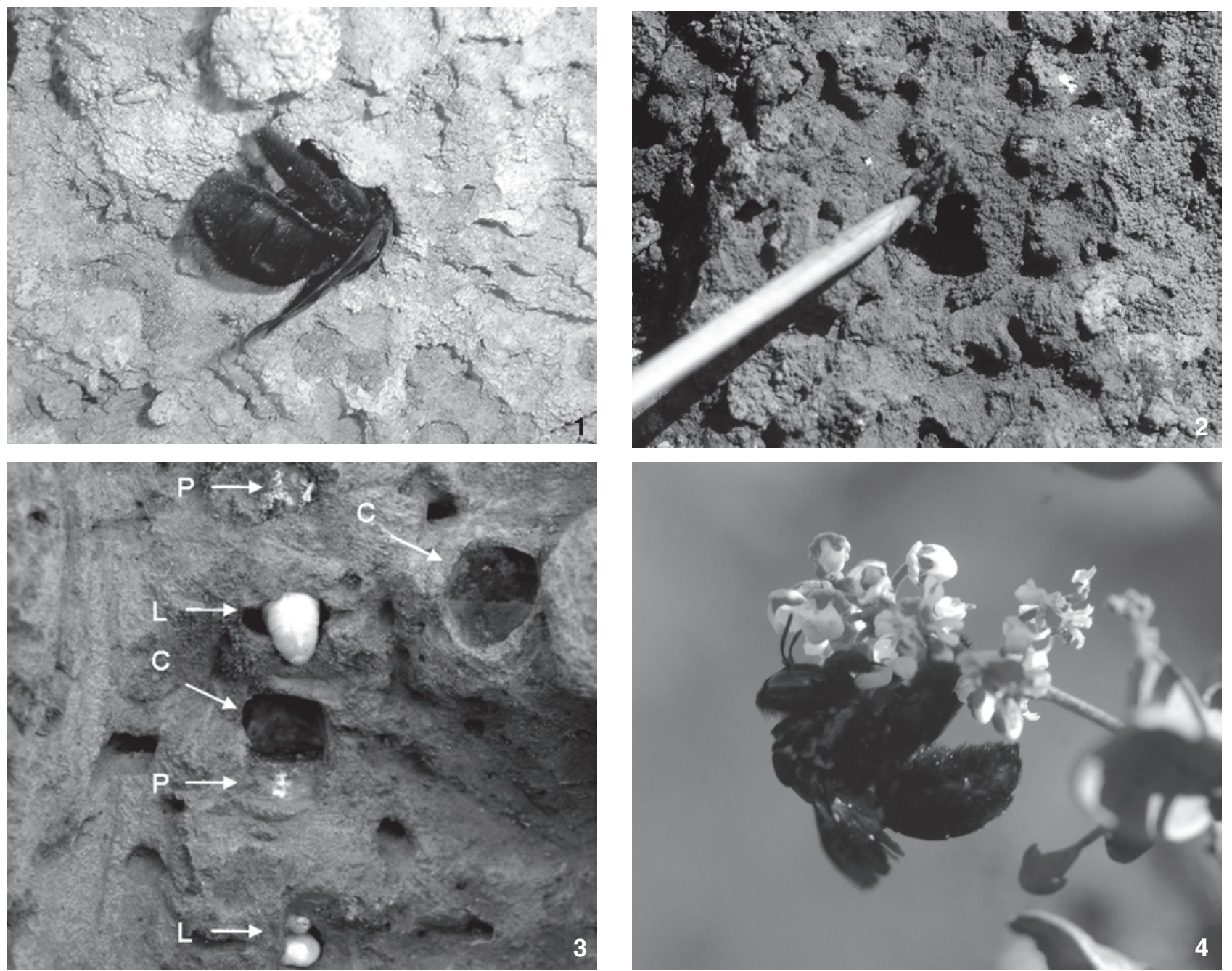

Figuras 1-4. Detalhes das fêmeas e do ninho de C. maranhensis acompanhado no cerrado de Urbano Santos, Maranhão: (1) fêmea escavando no termiteiro; (2) entrada do ninho após ser fechada pela fêmea; (3) detalhe do ninho depois de escavado; (4) fêmea coletando óleo em Byrsonima umbellata. (C) célula; (P) pólen; (L) larva.

anterior e posterior ficavam muito próximas, na parte inferior da célula, junto à massa de pólen.

O pólen, presente nas células, era pastoso e homogêneo e em células completas podia ocupar até metade do comprimento delas. A análise polínica de uma célula mostrou que havia 100\% de pólen de Byrsonima, possivelmente B. umbellata Mart., onde as fêmeas foram observadas coletando lipídios florais.

\section{Atividade nas flores}

De acordo com os inventários realizados no Nordeste do Brasil, C. maranhensis visita uma variedade de tipos florais pertencentes a seis famílias (Tab. I).

Fêmeas foram observadas forrageando em flores de Ouratea sp. (Ochnaceae) e Byrsonima umbellata Mart. (Malpighiaceae), apesar de diversas outras espécies vegetais flo- rescerem na área de estudo neste período, dentre elas outras Malpighiaceae, como Tetrapterys. Diferentes espécies de Centris foram vistas em visita às flores de Bowdichia virgilioides (Leg. Papilionoideae), porém C. maranhensis não foi observada visitando esta espécie. Diversos machos foram observados demarcando território ao redor de indivíduos ou grupos de indivíduos de B. umbellata.

Os adultos de C. maranhensis foram observados nas flores de $B$. umbellata no período de maio a agosto, sendo junho e julho os meses de maior abundância.

A coleta de pólen se deu por vibração, em flores de Ouratea sp. e a coleta de óleo foi observada em flores e botões de $B$. umbellata. Na coleta em flores, as fêmeas pousam sobre as mesmas e se prendem através das mandíbulas na pétala estandarte

Revista Brasileira de Zoologia 24 (4): 1006-1010, dezembro 2007 


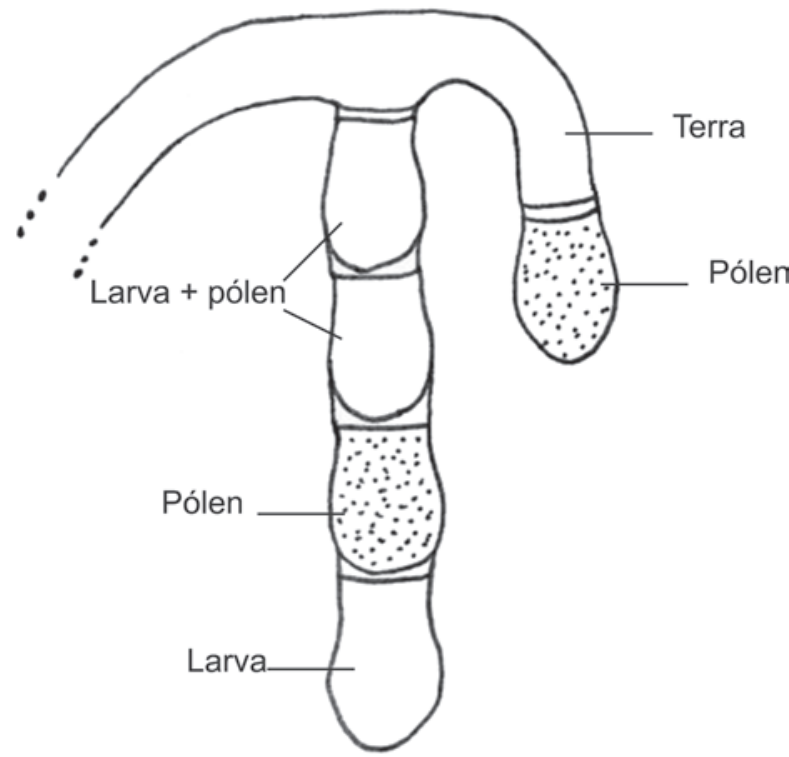

Figura 5. Esquema da disposição e conteúdo das células do ninho de Centris maranhensis encontrado em termiteiro no cerrado de Urbano Santos, Maranhão.

e com os pentes basitarsais, presentes nos dois primeiros pares de pernas, raspam os elaióforos, que acabam rompidos. O óleo liberado é então coletado e transferido para as escopas das pernas posteriores. Neste processo, a abelha pode transferir também os grãos de pólen que se encontram aderidos na sua superfície ventral, promovendo a polinização da flor. Embora a coleta de pólen não tenha sido observada diretamente, ela provavelmente ocorre, conforme sugerem os dados de análise polínica das células (Tab. I). No botão floral, as fêmeas equilibramse na própria inflorescência com auxílio das pernas posteriores e raspam todas as glândulas, transferindo o óleo para a escopa ao deixar o botão. Este comportamento é realizado em vôo estacionário próximo as inflorescências visitadas.

\section{DISCUSSÃO}

Os estudos atuais sobre espécies de Centris (Ptilotopus) sempre indicam uma associação com termiteiros (BENNET 1964, Coville et al. 1983, LAROCA et al. 1993, GaGLIANONE 2001). GAGLIANONE (2001) apresentou uma revisão sobre espécies de térmitas hospedeiros de Ptilotopus estudadas até então e também sobre os parasitas encontrados nos ninhos, geralmente pertencentes ao gênero Acanthopus Klug, 1807 (Hymenoptera, Apidae, Ericrocidini). No presente trabalho não foi observado qualquer espécie parasita, porém convém ressaltar que somente um ninho pôde ser observado.

A arquitetura do ninho de C. maranhensis é semelhante àquela encontrada em C. sponsa (LAROCA et al. 1993) e C. derasa (Vezey-Fitzgerald 1939, Bennet 1964), cujos ninhos são construídos em termiteiros arborícolas e C. scopipes (GAGLIANONE 2001), que nidifica em termiteiros epígeos. O número e disposição das células e a orientação do canal de entrada foi semelhante aos ninhos estudados por Bennet (1964) e Gaglianone (2001), que também encontraram ninhos com duas galerias, embora, segundo o primeiro autor, a presença de uma única galeria seja mais comum.

Bennet (1964) encontrou até 150 células velhas de $C$. derasa em um único termiteiro. De acordo com Gaglianone (2001), um mesmo termiteiro pode apresentar mais de um ninho com as células abandonadas de ninhos de anos anteriores incorporadas a ele. No presente estudo, embora tenham sido examinados outros termiteiros na área, nenhuma célula de $C$. maranhensis, além daquelas já descritas, foi encontrada.

Assim como neste trabalho, Gaglianone (2001) constatou que as células de cria não são facilmente mantidas em laboratório, a maioria delas sendo atacadas por fungos, o que também foi verificado pela autora nos próprios termiteiros.

A consistência pastosa e homogênea do pólen encontrado nas células de cria de C. maranhensis deve-se a uma camada superior oleosa, inicialmente líquida e que, mais tarde, incorpora-se à massa de pólen, conforme já descrito por GAGLIANONE (2001). Apesar de Centris (P.) maranhensis só ter sido observada coletando óleo em Byrsonima umbellata Mart., a totalidade de grãos de pólen desta espécie vegetal encontrada nas células de C. maranhensis reforça a importância de espécies deste gênero no forrageamento das abelhas de óleo. Além disso, as fontes de pólen utilizadas por $C$. maranhensis em diferentes ambientes foram, principalmente, espécies de Malpighiaceae que também fornecem óleo como recurso para estas abelhas.

Tabela I. Registros de coleta de Centris maranhensis em espécies florais de diferentes ecossistemas e os recursos oferecidos.

\begin{tabular}{llll}
\hline \multicolumn{1}{c}{ Espécie floral } & Recurso oferecido & Bioma & Autor \\
\hline Caesalpiniaceae - Senna spectabilis H.S.Irwin \& Barneby & Pólen & Caatinga & AGUIAR et al. 2003 \\
Malpighiaceae - Banisteriopsis sp. & Pólen, óleo & Cerrado & ALBUQUERQUE \& MENDONÇA (1999) \\
Fabaceae - Vatairea sericea (Ducke)Ducke & Pólen, néctar & Cerrado & ALBUQUERQUE \& MENDONÇA (1999) \\
Labiatae - Hyptis suaveolens (L.) Poit. & Néctar & Floresta & ReBÊO (1995) \\
Solanaceae - Solanum juripeba Rich. & Pólen & Cerrado & ReBÊO (1995) \\
Ochnaceae - Ouratea sp. & Pólen & Cerrado & Este trabalho \\
Malpighiaceae - Byrsonima umbellata Mart. & Pólen, óleo & Cerrado & Este trabalho \\
\hline
\end{tabular}


Esta é a primeira descrição para a atividade de nidificação de Centris maranhensis, o que amplia o conhecimento de espécies que utilizam ninhos de térmitas como substrato para nidificação.

\section{AGRADECIMENTOS}

Ao PROBIO-MMA pelos recursos financeiros, ao PIBIC/ CNPq e a FAPEMA pelas bolsas concedidas, respectivamente, à primeira e a segunda autora e à Comercial e Agrícola Paineiras Ltda. pelo apoio logístico na área de estudo. À Lea Carreira do MPEG pela identificação das lâminas polínicas e à Lúcia Macambira (MPEG) pela identificação da espécie de Amitermes.

\section{REFERÊNCIAS BIBLIOGRÁFICAS}

Aguiar, C.M.L. \& C.A. Garófalo. 2004. Nesting biology of Centris (Hemisiella) tarsata Smith (Hymenoptera, Apidae, Centridini). Revista Brasileira de Zoologia 21 (3): 477-486.

Aguiar, C.M.L. \& M.C. Gaglianone. 2003. Nesting biology of Centris (Centris) aenea Lepeletier (Hymenoptera, Apidae, Centridini) Revista Brasileira de Zoologia 20 (4): 601-606.

Aguiar, M.L.C.; F.C.V. Zanella; C.F. Martins \& C.A.L. de CarvaLHo. 2003. Plantas Visitadas por Centris spp. (Hymenoptera: Apidae) na Caatinga para Obtenção de Recursos florais. Neotropical Entomology 32 (2): 247-259.

Aguiar, C.M.L.; C.A. Garófalo \& G.F. Almeida. 2006. Biologia de nidificação de Centris (Hemisiella) trigonoides Lepeletier (Hymenoptera, Apidae, Centridini). Revista Brasileira de Zoologia 23 (2): 323-330.

Albuquerque, P.M.C. De \& J.A.C. MendonçA. 1999. Anthophoridae (Hymenoptera, Apidae) e Flora Associada em uma Formação de Cerrado no Município de Barreirinhas, MA, Brasil. Acta Amazônica 26: 45-54.

Bennett, F.D. 1964. Notes on the nesting of Centris derasa. PanPacific Entomologist 40 (2): 125-128.

Brasil. 1984. Diagnóstico dos principais problemas ambientais do Estado do Maranhão. São Luís, Lithograf, Ibama, Secretaria do Estado do Meio Ambiente e Turismo do Maranhão, 194p.

Buchmann, S.L. 1987. The ecology of oil flowers and their bees. Annual Review of Ecology and Systematics 18:343-369.

Camillo, E.; C.A. Garófalo \& J.C. Serrano. 1993. Hábitos de nidificação de Melitoma segmentaria, Centris collaris, Centris fuscata e Paratetrapedia gigantea (Hymenoptera, Anthophoridae). Revista Brasileira de Entomologia 37 (1): 145-156.

Coville, R.E.; G.W. Frankie \& S.B. Vinson. 1983. Nests of Centris segregata. (Hymenoptera: Anthophoridae) with a Review of the Nesting Habitats of the Genus. Journal of the Kansas Entomological Society 56 (2): 109-122.

ERDTMAN, G. 1969. Handbook of palynology: an introduction to the study of pollen grains and spores. Copenhagen, Munksgaard, 486p.

Gaglianone, M.C. 2001. Nidificação e forrageamento de Centris (Ptilotopus) scopipes Friese (Hymenoptera, Apidae). Revista Brasileira de Zoologia 18 (Supl. 1): 107-117.

Jesus, B.M.V. \& C.A. Garófalo. 2000. Nesting behaviour of Centris (Heterocentris) analis (Fabricius) in southeastern Brazil (Hymenoptera, Apidae, Centridini). Apidologie 31: 503-515.

Laroca, S.; D.T. Reynaud dos Santos \& D.L. Schwartz Filho. 1993. Observations on the nesting biology of three Brazilian centridini bees: Melanocentris dorsata (Lepeletier, 1841), Ptilotopus sponsa (Smith, 1854) and Epicharitides obscura (Friese, 1899) (Hymenoptera: Anthophoridae). Tropical Zoology 6: 153163.

Pereira, M.; C.A. Garófalo; E. Camillo \& J.C. Serrano. 1999. Nesting biology of Centris (Hemisiella) vittata Lepeletier in southeastern Brazil (Hymenoptera, Apidae, Centridini). Apidologie 30: 327-338.

RebêLo, J.M.M. 1995. Espécies de Anthophoridae (Hymenoptera, Apoidea) e sua associação com flores, numa área restrita da ilha de São Luís-MA. Boletim do Museu Paraense Emílio Goeldi 11 (2): 105-124.

RebêLo J.M.M.; M.M.C. Rêgo \& P.M.C. De Albuquerque. 2003. Abelhas (Hymenoptera, Apoidea) da região setentrional do Estado do Maranhão, Brasil, p. 265-278. In: G.A.R. Melo \& I. Alves-Dos-SAntos (Eds). Apoidea Neotropica: homenagem aos 90 anos de Jesus Santiago Moure. Criciúma, Editora UNESC, XVI+320p.

Rêgo, M.M.C.; P.M.C. De Albuquerque; M.C. Ramos \& L.M. CarREIRA. 2006. Aspectos da biologia de nidificação de Centris flavifrons (Friese) (Hymenoptera: Apidae, Centridini), um dos principais polinizadores do murici (Byrsonima crassifolia L. Kunth, Malpighiaceae), no Maranhão. Neotropical Entomology 35 (5): 579-587.

Silva, F.O.; B.F. Viana \& E.L. Neves. 2001. Biologia e Arquitetura de ninhos de Centris (Hemisiella) tarsata Smith (Hymenoptera: Apidae: Centridini). Neotropical Entomology 30 (4): 541545.

Vesey-Fitzgerald, D. 1939. Observations on bees in Trinidad, B.W. I. Proceedings of the Royal Entomological Society 14: 107110.

VianA, B.F. 1999. A Comunidade de Abelhas (Hymenoptera: Apoidea) das Dunas Interiores do Rio São Francisco, Bahia, Brasil. Anais da Sociedade Entomológica do Brasil 28 (4): 635-645.

Recebido em 17.V.2007; aceito em 19.XI.2007. 